Fecha de recepción: mayo 2021 Fecha de aceptación: junio 2021 Versión final: julio 2021

\section{Apropiación, restitución y elaboración identitaria en la serie Televisión por la Identidad}

Fabricio Laino Sanchis ${ }^{(1)}$ y Victoria Alvarez ${ }^{(2)}$

Resumen: Durante la última dictadura militar argentina, alrededor de 500 niños y niñas fueron apropiados en el marco del plan sistemático de desaparición de personas. Desde ese entonces, familiares y organismos de derechos humanos, en especial Abuelas de Plaza de Mayo, emprendieron la lucha por localizarlos/as y restituirlos/as a sus legítimas familias. En este proceso elaboraron diferentes conceptos y representaciones en torno a la cuestión de la identidad subjetiva y su relación con la genética, el parentesco, la memoria y la historia. A comienzos de los años 2000, la causa de Abuelas tomó mayor impulso, en gran medida porque muchos/as niños/as apropiados/as, por entonces ya jóvenes, emprendieron por iniciativa propia la búsqueda de sus verdaderos orígenes, lo que llevó a un aumento de las restituciones y una mayor visibilidad de las mismas. En este contexto, Abuelas promovió diferentes iniciativas culturales y mediáticas con el objetivo de consolidar la legitimidad social de su causa y llegar a sus principales destinatarios: los jóvenes que dudaban sobre su verdadera identidad biológica. Una de estas iniciativas fue Televisión por la Identidad, una miniserie de tres capítulos emitida por el canal Telefé en el año 2007. La serie alcanzó una gran audiencia y repercutió de manera notable en la difusión del mensaje de Abuelas.

En este artículo nos proponemos estudiar esta producción audiovisual para indagar qué sentidos construye en torno a la noción de "identidad". Para ello analizaremos su contexto de producción y la estructura narrativa de sus tres capítulos, lo que nos permitirá indagar en los discursos y representaciones sobre el delito de la apropiación y los procesos de búsqueda y restitución que allí aparecen. Mostraremos de qué manera estos procesos aparecen ligados a la construcción de la identidad de los nietos/as restituidos/as, tanto en una dimensión biológica como también familiar, social y subjetiva.

Palabras clave: Televisión por la Identidad - Abuelas de Plaza de Mayo - Representaciones - Apropiación de niños y niñas - Restitución - Terrorismo de Estado.

[Resúmenes en inglés y portugués en la página 73]

(1) Doctor en Historia por la Universidad Nacional de San Martín y profesor de Enseñanza media y Superior en Historia por la Universidad de Buenos Aires. Se desempeña en la Universidad Nacional de Avellaneda y en la Universidad de Buenos Aires. Es becario 
postdoctoral del CONICET. Integra distintos proyectos de investigación vinculados con la historia reciente argentina y el proyecto "Questioning Traumatic Heritage: Spaces of Memory in Europe, Argentina, Colombia-SPEME”.

(2) Doctora en Estudios de Género por la Universidad de Buenos Aires, Magíster en Historia y Memoria por la Universidad Nacional de La Plata y profesora de Enseñanza media y Superior en Historia por la UBA. Se desempeña como docente en la Universidad de Buenos Aires y como becaria postdoctoral del CONICET. Integra distintos proyectos de investigación vinculados con la historia reciente argentina y el proyecto "Questioning Traumatic Heritage: Spaces of Memory in Europe, Argentina, Colombia-SPEME”.

\section{Introducción}

Durante la vigencia del terrorismo de Estado en la Argentina, en especial bajo el último gobierno militar (1976-1983), alrededor de 500 niños/as fueron apropiados por las fuerzas armadas y de seguridad. Algunos/as de estos/as niños/as habían sido secuestrados/as junto con sus madres y padres, mientras que muchos/as otros/as nacieron durante el cautiverio en los centros clandestinos de detención de sus madres embarazadas. Los represores o sus allegados los inscribieron como hijos/as propios/as o los/as adoptaron mediante procedimientos fraudulentos, ocultándoles su historia y sus orígenes y rompiendo todo vínculo con sus familias biológicas.

Este crimen derivó en una tarea específica en la lucha de los familiares y los organismos de derechos humanos que se oponían a la dictadura: la búsqueda y restitución de aquellos niños y niñas a sus familias biológicas. Con este fin, en 1977 se creó una pequeña agrupación de "madres-abuelas" dentro de Madres de Plaza de Mayo, que con el tiempo se autonomizaría y se transformaría en Abuelas de Plaza de Mayo (Abuelas) (Laino Sanchis, 2020a). Desde entonces, Abuelas se ha transformado en la emprendedora protagónica de la causa por la restitución de los/as niños/as apropiados/as. Para obtener apoyo social y la difusión de su reclamo, desde muy temprano la organización ideó diferentes estrategias y tejió vínculos con diversos actores sociales y políticos, a nivel local, nacional e internacional: profesionales, científicos, artistas, organizaciones internacionales, sindicatos, partidos políticos, entre muchos otros. Dentro de este amplio espectro se ha destacado el vínculo con el campo artístico, que en sus diferentes manifestaciones ha resultado particularmente fructífero.

Desde la década de 1980, documentales y ficciones cinematográficas y televisivas han tematizado la apropiación de niños y niñas, la lucha de Abuelas de Plaza de Mayo y otros familiares por recuperarlos y, más recientemente, los difíciles procesos de construcción identitaria y elaboración de los pasados familiares que atraviesan los/as nietos/as restituidos/as. Una de estas iniciativas fue Televisión por la Identidad, una miniserie televisiva 
de tres capítulos dirigida por Miguel Colom y emitida por el canal Telefé en el año 2007. La serie alcanzó una gran audiencia y repercutió de manera notable en la difusión del mensaje de Abuelas.

Por el impacto que tuvo, resulta significativo analizar esta producción audiovisual para indagar qué representaciones y sentidos elabora en torno a las apropiaciones, las restituciones y la noción de "identidad". Así, en primer lugar, situaremos a la obra en su contexto de producción, vinculado no solo con los acontecimientos políticos y sociales, sino especialmente con el momento de la memoria sobre el pasado reciente y la trayectoria histórica de la causa de Abuelas. En segunda instancia, analizaremos los tres capítulos que la componen. Observaremos la participación directa y activa de Abuelas tanto en el guion como en la producción, que se percibe en la construcción argumental y en el uso de conceptos y figuras propias de la organización. En última instancia, veremos cómo, con las particularidades de cada caso, los capítulos muestran los diferentes procesos de restitución ligados a la construcción de una "verdadera identidad" de los/as nietos/as restituidos/ as, con la presencia de tópicos clásicos del discurso de Abuelas, como el de las triadas apropiación-mentira-esclavitud vs. restitución-verdad-libertad y el "llamado de la sangre".

\section{La causa de Abuelas en la década del 2000: consenso social y legitimación estatal}

Televisión por la Identidad se filmó y emitió en un momento histórico en el que la causa de Abuelas de Plaza de Mayo ya había alcanzado una importante legitimidad estatal y un amplio consenso social, y en el que los "nietos restituidos" ocupaban una presencia cada vez mayor como figuras públicas. Desde 1996, en el marco de un proceso de proliferación de testimonios de perpetradores y sobrevivientes del terrorismo de Estado y de una reactivación de la lucha del movimiento de derechos humanos que Lvovich y Bisquert (2008) denominaron "boom de la memoria", la cuestión de la apropiación de niños y niñas durante la dictadura ocupó un papel central en la instalación de la discusión pública sobre los delitos de la última dictadura y, en especial, en la erosión de las leyes de impunidad. La denuncia penal presentada a fines de 1996 por integrantes de Abuelas y otros querellantes, conocida como "Plan sistemático de apropiación de menores" tuvo un gran impacto judicial y político, ya que provocó el arresto de importantes figuras del régimen militar como Videla y Massera, generó importantes repercusiones en los medios de comunicación, obligó a los diferentes sectores políticos a tomar posición sobre el tema y fue la punta de lanza que permitió la introducción en los tribunales federales de la noción de "crimen de lesa humanidad" y de otras categorías provenientes de instrumentos y de la jurisprudencia internacional en derechos humanos.

Este proceso de mayor repercusión pública de la cuestión se dio en el marco de importantes transformaciones en las características de la causa de Abuelas. Los sujetos que eran buscados para ese entonces habían dejado de ser niños y niñas para convertirse en jóvenes en tránsito a la adultez. Tomando conciencia de esta realidad, desde 1997 Abuelas encaró 
una serie de acciones públicas que interpelaban directamente a esos nietos o nietas que debían salir a la búsqueda de su "verdadera identidad": intervenciones artísticas, campañas gráficas y spots televisivos. Estas transformaciones en las estrategias y el repertorio de acción, como ocurrió en general con el movimiento de derechos humanos, provino en parte el impulso dado por la "generación de los hijos", cuya principal expresión pública fue la agrupación Hijos por la Identidad y la Justicia contra el Olvido y el Silencio (H.I.J.O.S.). Dentro de Abuelas, un grupo de nietas (algunas restituidas, otras que buscaban a sus hermanos apropiados) que participaba desde fines de la década de 1980 tomó mayor protagonismo dentro de la organización, a la que también se sumaron a colaborar y participar otros/as jóvenes, muchos/as de ellos/as en el marco de los proyectos iniciados con algunas universidades nacionales.

En el desarrollo de estas nuevas acciones y en el crecimiento del apoyo social de Abuelas fue muy relevante la construcción de alianzas y lazos de cooperación con representantes e instituciones de diferentes esferas de la vida política y social, en particular con el campo cultural y académico (De Vecchi Gerli, 2010). Si bien diferentes artistas y colectivos habían apoyado la lucha de Abuelas desde sus inicios y habían realizado acciones durante los años ' 80 y comienzos de los '90, desde fines de esta década se dio un salto cuantitativo y cualitativo en las iniciativas. Surgieron emprendimientos artísticos institucionalizados, como Teatro x la Identidad, que se consideró a sí mismo como el "brazo artístico" de Abuelas de Plaza de Mayo (Diz, 2016). Abuelas logró convocar a músicos y artistas plásticos de gran reconocimiento y popularidad en eventos que resultaron muy convocantes, como Rock por la Identidad y la muestra Identidad del Centro Cultural Recoleta (instalación colectiva con la participación de trece artistas, como León Ferrari y Luis Felipe Noé). Las alianzas con el mundo de la cultura le permitieron a Abuelas alcanzar un alto grado de conocimiento y una gran aceptación social de su causa, logrando al mismo tiempo una creciente llegada a los jóvenes, convertidos en los destinatarios principales de su mensaje. Gracias a esto, y a pesar de la inestabilidad política y de los cambios constantes en la orientación del gobierno nacional, en estos años Abuelas pudo seguir consolidando y jerarquizando el marco legal e institucional para la localización e identificación de los ya por entonces jóvenes buscados. En este sentido, el periodo de legitimación estatal que comenzó con el gobierno de Néstor Kirchner (2003-2007) y continuó con los dos mandatos de Cristina Fernández de Kirchner (2007-2015) puede comprenderse como una reafirmación oficial de un largo proceso de construcción de consenso social que había tomado un nuevo impulso a fines de la década de 1990.

La asunción de Néstor Kirchner a la presidencia marcó un giro en las políticas estatales de memoria y justicia transicional. Se reabrieron los procesos judiciales contra los represores (cuyos crímenes pasaron a ser considerados como delitos de lesa humanidad y, por ende, imprescriptibles), se promovió la recuperación de ex centros clandestinos de detención y su conversión en espacios de memoria y se comenzó a reivindicar pública y oficialmente la militancia de izquierda de los años '70 y la trayectoria de los organismos de derechos humanos, en particular de Madres y Abuelas de Plaza de Mayo. Durante estos años, Abuelas de Plaza de Mayo y los "nietos restituidos" alcanzaron una enorme presencia en la agenda pública nacional y se produjeron numerosas restituciones. En este camino se reforzaron 
instituciones y agencias preexistentes (como el Banco Nacional de Datos Genéticos y la Comisión Nacional por el Derecho a la Identidad) y se impulsaron otras nuevas (como la Unidad Fiscal Especializada para Casos de Apropiación de Niños durante el Terrorismo de Estado -UFICANTE).

En estos años de consolidación de su causa, con el apoyo de amplios sectores de la cultura primero, y luego también del Estado, las producciones audiovisuales ocuparon un lugar muy relevante, apuntaladas en muchos casos por el apoyo del financiamiento estatal. Entre 1999 y 2015 se filmaron más de una docena de documentales y ficciones cinematográficas dedicadas a la apropiación de niños/as, la lucha de Abuelas y los procesos de restitución de identidad ${ }^{1}$. En cuanto a la televisión, además de múltiples spots publicitarios se realizaron diversas series televisivas de ficción (como Televisión por la identidad y Montecristo, ambas emitidas por la cadena Telefé, y Volver a Nacer, emitida por la TV Pública) y documentales (entre las que destacan diversas miniseries producidas por Canal Encuentro, como Nietos, historias con identidad, Acá estamos y 99,99\%. La ciencia de las Abuelas). También se produjeron contenidos adaptados al público infantil para el canal público Paka Paka.

\section{"Este no es un programa más"}

En este contexto de aumento del interés por el tema, de la mano del impulso estatal y con un auge de producciones audiovisuales, surgió Televisión por la Identidad. La miniserie tuvo como antecedente la telenovela Montecristo, realizada por Miguel Colom y el mismo equipo de guionistas y producida y emitida también por Telefé en el año 2006. Esta adaptación de la novela homónima de Alejandro Dumas fue la primera ficción del prime time de la televisión abierta argentina que puso en el centro de su trama la desaparición de personas durante la última dictadura militar y la apropiación de los hijos y las hijas de desaparecidos/as. Su éxito fue notable: alcanzó niveles de audiencia muy altos y tuvo una recepción muy positiva por parte de los medios de comunicación y la crítica especializada, que remarcaron el abordaje político-pedagógico de la tira, inusual en su género (Landau, 2006; Soler Azorín, 2015). El impacto para la causa de Abuelas fue enormemente significativo, casi una bisagra en la historia de la organización y del problema social de la apropiación de niños y niñas. De esta manera lo recuerda Clarisa Veiga, que participa en la organización desde 1997 y en la actualidad es la coordinadora del área de Prensa y Difusión:

Para mí Montecristo es la legitimación social de la búsqueda de las Abuelas. Fue impresionante (...) toda la institución, todas las áreas atendían llamados y recibían consultas porque desbordó. Es como si te dijera en tres meses 600 personas vinieron con dudas sobre su identidad (C. Veiga, comunicación personal, 29 de junio de 2018). 
Tras el éxito de Montecristo y el interés demostrado por una parte de la audiencia, entre su equipo de realización y Abuelas surgió la idea de hacer una serie de ficción basada en casos reales de apropiación y de restitución de identidad. Telefé aceptó el proyecto y fue producido por Telefé Contenidos, dirigido por Claudio Villarruel y Bernarda Llorente. En la búsqueda de un producto de calidad el canal supuso un importante esfuerzo de producción, con tiempos de rodajes y de posproducción de cada capítulo muy superiores a la media. "Este no es un programa más", afirmaba Villarruel al diario La Nación, definiendo a la tira como un telefilm en tres entregas (Trzenco, 2007).

La serie salió al aire el lunes 22 de octubre de 2007, en coincidencia con el trigésimo aniversario de la creación de Abuelas (día que en 2004 se instituyó por la ley nacional 26.001 como Día Nacional por el Derecho a la Identidad). A lo largo de tres capítulos, narraba diferentes historias de jóvenes que habían sido apropiados y habían podido recuperar su verdadera identidad biológica y reencontrarse con sus familias. Los dos primeros capítulos estaban enteramente basados en la historia de dos jóvenes restituidos: la de Tatiana Sfiligoy Ruarte Britos (y su hermana, Laura), el primero; y la de Juan Cabandié, el segundo. El tercer capítulo, en cambio, presentaba una historia ficcional construida sobre fragmentos de diferentes casos reales.

$\mathrm{Al}$ igual que Montecristo, la miniserie tuvo una gran valoración del público y de la crítica. La audiencia de las tres emisiones llegó a guarismos de rating similares a los de Gran Hermano y Showmatch, los programas de entretenimiento más vistos en las televisión abierta ese año (Stiletano, 2007). Tal fue el éxito que Telefé decidió reponerla en julio de 2008. Las reseñas del periodismo de espectáculo, en general favorables, destacaban su compromiso con una temática sensible y también su apuesta técnica y el gran nivel actoral. Entre 2007 y 2008, obtuvo importantes distinciones nacionales e internacionales: cuatro premios Martín Fierro, tres premios Clarín Espectáculos y el Emmy Internacional a la mejor película de televisión o miniserie en 2008.

Como puede verse en su gestación, Televisión por la Identidad fue ante todo una apuesta política, con un tono didáctico y cierta expectativa instrumental, que formó parte del vasto entramado de iniciativas culturales promovidas o fomentadas por Abuelas de Plaza de Mayo para difundir su lucha por la restitución de sus nietos y nietas y por la concientización del derecho a la identidad. No solo la propuesta llegó de Abuelas y contó con su partición activa en diferentes etapas de la producción y realización (en especial, en el guion, que fue revisado y comentado por los nietos restituidos cuyos casos eran representados), sino que también realizadores, productores, guionistas y actores coincidían en que la serie debía ser un aporte concreto en la búsqueda de las personas que aún desconocían sus verdaderos orígenes biológicos. En una entrevista al diario Página 12, Villarruel y Llorente afirmaban:

Nos da mucho placer. Es uno de esos programas en los que el músculo que más trabaja es el corazón. Hacerles un homenaje a Abuelas de Plaza de Mayo no puede no ser movilizante. Conocer cómo lucharon contra el monopolio del poder y el terror sin más que la búsqueda de sus hijos y nietos a través de un ciclo unitario como Televisión por la identidad es una gran alegría y una devo- 
lución, aunque mínima, a esas madres y abuelas que son ejemplo de fortaleza y dignidad. Es el momento más pleno de nuestro trabajo como comunicadores. (Respighi, 2007: 1)

En sentido similar se expresaba Marcelo Camaño, uno de los guionistas: "la búsqueda de Abuelas continúa, y si esto sirve para que el público pase una hora conmovedora y, de paso, ayuda a alguien a encontrar su identidad, mejor".

Como esperaban sus productores y realizadores, la serie tuvo un enorme impacto para la causa de Abuelas. Marcelo Castillo, director del Archivo Biográfico Familiar de la organización, recuerda que "toda Abuelas durante ese tiempo estuvo atendiendo teléfonos. Todos dejamos de hacer lo que estábamos haciendo y todas las filiales, todo, era una cantidad de gente que vino impresionante" (M. Castillo, comunicación personal, 23 de mayo de 2018). Tatiana Sfiligoy Ruarte Britos, cuya historia es retratada en el primer capítulo, relata que después de la emisión de la serie mucha gente la frenaba en la calle o en el supermercado para preguntarle si era "Tatiana, la de Televisión por la Identidad" (T. Sfiligoy Ruarte Britos, comunicación personal, 19 de julio de 2017).

Televisión por la Identidad puede pensarse en sintonía con otras iniciativas de Abuelas "por la identidad": Teatro por la Identidad, Música por la Identidad, Deporte por la Identidad, Twitterealtos por la Identidad, entre muchas otras. En efecto, la categoría "identidad" y la idea de la lucha por ella se ubicaron en el centro de la acción y del discurso público de Abuelas. Este concepto había comenzado a ocupar un lugar significativo en el discurso público y en el armazón argumental de la organización desde los años '80, densificándose a partir de la incorporación de elementos teóricos provenientes de diferentes disciplinas (Quintana, 2016). Sin embargo, a fines de los años '90 se produjo un desplazamiento semántico, una importante resignificación de la categoría. La noción de "derecho a la identidad" comenzó a hacer referencia no tanto ya al derecho de los sujetos a ser criados con sus familias biológicas sino a su derecho, como jóvenes o adultos/as, a conocer y reconocer su verdadero origen biológico, la historia de sus padres y madres, entendiendo que el conocimiento de esta verdad era fundamental, si no indispensable, en la construcción de la identidad personal. En este mismo sentido, el significante "restitución" comenzó a resemantizarse para dejar de referirse a la reincorporación de un/a niño/a su "legítima" familia biológica y transformarse, en cambio, en sinónimo de reconocimiento de la verdad o de la identidad biológica y, como consecuencia, de la identidad y la memoria familiar. Las connotaciones de esta renovada apelación al "derecho a la identidad" pueden observarse en las acciones y en las campañas de difusión, tanto gráficas como televisivas, desarrolladas por Abuelas a partir de estos años. Al dirigirse a los y las jóvenes que podían llegar a sospechar de sus orígenes familiares como destinatarios privilegiados/as de su mensaje, la lucha "por la identidad" suponía un llamado a poner en cuestión los relatos heredados, a preguntarse sobre los propios orígenes en un momento de la vida (el final de la adolescencia, el comienzo de la vida adulta) en el que toda persona se suele plantear numerosos dilemas que hacen a la constitución de la subjetividad. La consigna central de las campañas desde 1997, "Y vos, ¿sabés quién sos?", mostraba de qué manera el reconocimiento de la verdadera filiación era conceptuado como elemento central en la elaboración 
de la identidad. Era, a la vez, una apuesta a despertar la duda, en tanto principio movilizador que podía impulsar a emprender el camino de la búsqueda de la verdadera identidad (Arreche, 2012; Diz, 2016). Por eso la otra consigna que acompañaba las acciones de Abuelas a partir de estos años convocaba a los y las jóvenes a acercarse a la organización: "Si tenés dudas sobre tu identidad y creés que podés ser hijo de desaparecidos, comunicate con Abuelas de Plaza de Mayo"2.

Como veremos a continuación, estas y otras elaboraciones en torno al problema de la identidad aparecen, con diferentes modulaciones, en los capítulos de Televisión por la Identidad.

\section{Tatiana}

El primer capítulo de la miniserie, “Tatiana”, relata la historia de las hermanas Tatiana Sfiligoy Ruarte Britos y Laura Sfiligoy Jotar Britos, cuya restitución fue la primera producida en territorio argentino, en el año 1980, cuando aún gobernaban los militares ${ }^{3}$. Su caso es relativamente atípico dentro de las historias de las historias de apropiación. En octubre de 1977, su madre, Mirta Britos y su compañero, Alberto Jotar (padre de Laura) fueron secuestradas por las fuerzas represivas y las niñas resultaron abandonadas en una plaza de Villa Ballester (el padre de Tatiana, Oscar Ruarte, había sido secuestrado un año antes). El juez del Tribunal de Menores $N^{\circ} 2$ de San Martín, Mario Basso, que recibió a las niñas, las ingresó como "NN" (a pesar de que Tatiana sabía su nombre, el de su hermana y el de su madre), las separó y las derivó a dos institutos de menores, sin realizar ninguna de las averiguaciones de paradero de familiares que establecía la ley. Las niñas fueron adoptadas por Carlos e Inés Sfiligoy, que desconocía el trágico destino de sus padres biológicos. Según diferentes fuentes, allegados a los Sfiligoy habrían advertido a Abuelas de Plaza de Mayo, que se contactaron con ellos y encontraron buena receptividad de su parte. Las familias biológicas de las niñas consensuaron que siguieran viviendo con sus padres adoptivos y estos aceptaron que las abuelas pudieran verlas y que las niñas conocieran plenamente sus orígenes y su historia.

La primera parte del capítulo muestra la vida plena, feliz y comprometida de Mirta, Alberto y sus hijas antes de la irrupción del terrorismo de Estado en sus vidas. El secuestro y desaparición de los cuatro marca un quiebre trágico, un antes y un después que trastorna por completo y pone en desconcierto a la familia ampliada, en especial a las abuelas de las niñas. Se trata del esquema narrativo que aparece con frecuencia en los relatos de los familiares de las víctimas del terrorismo de Estado, en especial de las madres y abuelas, y que aparece con frecuencia en las representaciones testimoniales y ficcionales (Filc, 1997; Quintana; 2016).

El secuestro de la madre, el abandono de las niñas y la inacción del juez que debe hacerse cargo de ellas son nodales dentro de la trama. El capítulo discute el argumento de los represores, sus abogados defensores y apologistas de que ellos no eran apropiadores, sino que eran los padres "subversivos" los que abandonan a sus hijos/as. En este punto, el 
guion retoma argumentos desarrollados desde los años ' 80 por Abuelas; en sintonía con el didactismo de la serie, en un pasaje un grupo de Abuelas esgrime de manera explícita estos argumentos frente a un juez: las niñas no fueron abandonadas, fueron apropiadas. El capítulo remite también a los inicios de la lucha de Abuelas y los primeros procesos de búsqueda y restitución de los/as niños/as apropiados/as. Se representan las "tareas detectivescas" que caracterizaron a la organización en estos primeros años: las reuniones de incógnito en el bar Las Violetas, con nombres en clave, las aproximaciones a las niñas con diferentes artilugios, acciones que por su fuerte componente performático María Luisa Diz (2019) ha denominado "tácticas dramáticas".

Las escenas finales muestran la localización de las niñas por parte de sus abuelas y la restitución consensuada, en la que ellas siguen viviendo con sus padres adoptivos conociendo sus verdaderos orígenes y vinculadas a su familia biológica. Al exponer los temores de los padres adoptivos a que les "quiten" a las niñas y mostrar la predisposición de Abuelas a dialogar con esta familia, la serie aborda otro elemento histórico del discurso de Abuelas: la diferenciación entre la adopción y la apropiación. Con las familias que hubieran adoptado "de buena fe", sin estar vinculados con la represión, siguiendo los caminos legales, desconociendo el origen de los/as niños/as, se podía entablar un diálogo y buscar soluciones consensuadas. Por el contrario, era imposible pensar en que los niños y las niñas quedaran en manos de personas que se hubieran apropiado de ellos/as y que estuvieran ligados, directa o indirectamente, con su secuestro y el de sus padres y madres. Esta distinción había sido formulada desde muy temprano por Abuelas en su discurso público en cierta medida como respuesta de los sectores que las acusaban de poner en duda la institución de la adopción y a todos los padres y madres adoptivos/as (Laino Sanchis, 2018).

El capítulo concluye con el testimonio de la verdadera Tatiana en un acto junto a su hija mayor, con diferentes reflexiones sobre su experiencia de vida y la reivindicación de la lucha de Abuelas: "cada nieto encontrado es como volver a nacer". Este mismo procedimiento de incluir fragmentos de testimonios reales se repetirá en los siguientes capítulos.

\section{Juan}

El segundo capítulo, “Juan”, se centra en la historia de la apropiación y restitución de identidad de Juan Cabandié, cuya historia se hizo muy conocida por esos años. Damián Cabandié y Alicia Alfonsín, militantes de la Juventud Peronista, fueron secuestrados el 23 de noviembre de 1977. Alicia estaba embarazada de cinco meses. Estuvieron detenidos en los centros clandestinos de detención "El Banco" y "Club Atlético". En diciembre, Alicia fue trasladada a la ESMA, donde funcionaba una "maternidad" clandestina. Allí dio a luz en marzo de 1978 a un varón, al que llamó Juan. El bebé fue separado de la madre a los pocos días y entregado a Luis Antonio Falco, personal de la Policía Federal. Con su esposa, Teresa Perrone, lo anotaron como hijo propio, con el nombre de Mariano. En el año 2003, a partir de diversas dudas e interrogantes sobre su identidad, el joven se acercó a Abuelas de Plaza de Mayo y a la CONADI. El 26 de enero del 2004, los análisis del Banco Nacional 
de Datos Genéticos confirmaron que era Juan, hijo de Damián Cabandié y Alicia Alfonsín, nacido en la ex-ESMA.

El relato se desplaza constantemente entre tres tiempos: la niñez de Juan con sus apropiadores, que lo han bautizado Mariano; un pasado más reciente, cuando un joven Mariano empieza a dudar de sus orígenes; y el presente del relato, en el que ahora Juan, gracias a Abuelas, la CONADI y los resultados de los análisis genéticos, ha podido recuperar su verdadera identidad y se encamina a reencontrarse con su familia biológica y su pasado. A partir de esta estructura narrativa, modula uno de los tópicos clásicos en el discurso de Abuelas: el dilema del nombre como expresión de la duplicidad identitaria que viven los jóvenes apropiados, una existencia dividida entre una identidad falsa y una identidad verdadera. La identidad verdadera (marcada por la filiación, por el lazo de sangre) vive atrapada pero latente bajo el velo de la identidad falsa impuesta por los apropiadores. Aquella identidad verdadera, desaparecida/apropiada pero realmente presente, podía reaparecer en cualquier momento y esta era una necesidad vital, un momento indispensable para lograr genuina elaboración de la subjetividad. Esta concepción se anclaba en una interpretación que se remontaba a las primeras elaboraciones de Abuelas sobre la cuestión de la identidad, en los años ' 80 , y engarzaba los pares dicotómicos identidad falsa/identidad verdadera con los de esclavitud/libertad: mientras la "mentira" vivida con la familia apropiadora constituía una forma de "esclavitud", la "verdad" otorgaba la "libertad" que permitía recorrer un nuevo camino identitario.

Un elemento vinculado a esta idea de identidad dividida, duplicada, que aparece con frecuencia en spots televisivos, campañas gráficas y otras iniciativas artísticas, es la cuestión del nombre. Como señala Da Silva Catela, el nombre no es un dato menor de la biografía personal, sino que es un elemento fundamental en la inscripción individual dentro del espacio social:

El nombre y el apellido evocaban así una inserción en el espacio y en lazos de consanguinidad específicos. Como término relacional establecían la conexión entre el espacio vivido por y del grupo, frente a los OTROS (Da Silva Catela, 2005: 136).

Como señala la autora recuperando las ideas de Bourdieu, el nombre propio es el elemento que constituye una "identidad social constante y durable" (Da Silva Catela, 2005, p. 137). Es, para decirlo con Ricoeur, un componente fundamental de la mismidad, es decir, de aquello de la identidad que pervive inalterable en el tiempo, idéntico a sí mismo (Ricoeur, 1996). La apropiación, sin embargo, supuso la supresión de esos nombres y apellidos y, por ende, la ruptura de esos sistemas de referencia, la des-inscripción de los niños y las niñas de sus redes de parentesco y la disociación entre el sujeto y ese nivel primario y en teoría inalterable de la identidad. A través de su "militancia del sentido", como la ha llamado Gabriel Gatti (2011), Abuelas buscaba suturar ese quiebre producido por el terrorismo de Estado, religando a los/as jóvenes apropiados/as, los "desaparecidos vivos", con su verdadero nombre, elemento fundante de su identidad. A través de sus mensajes, dirigidos a aquellos/as que estaban viviendo esa situación de duplicidad identitaria, la organización 
intentaba mostrar las consecuencias de la pérdida del nombre y, al mismo tiempo, resaltar la importancia de su recuperación.

Todos estos elementos aparecen en "Juan". Una de las primeras escenas nos muestra a Mariano de niño realizando el trámite del DNI. La escena cierra con una imagen de su documento con el nombre que le dieron los apropiadores (Mariano Falco), al que se le sobreimprime, como un negativo, el verdadero (Juan Cabandié). Avanzada la trama, cuando empieza a sospechar sobre sus orígenes, Mariano sueña que una mujer embarazada lo llama Juan. Cuando en la CONADI le confirman que es hijo de desaparecidos, lo primero que pregunta es “¿cómo me llamo?”. En la siguiente escena de esa secuencia se encuentra con su hermana y le dice "siento una libertad enorme, me llamo Juan". Cuando Juan, de camino a la sede de Abuelas para encontrarse con su familia biológica, manifiesta sus temores ante esta nueva realidad que se le ha revelado, su hermana lo anima: "Ahora tenés todo un pasado por delante". La libertad de conocer la identidad biológica, los orígenes y el nombre verdadero, es el primer paso para reconstruir la historia personal y familiar y poder así elaborar de forma genuina la identidad subjetiva.

La historia de Juan se constituye como el paradigma del joven que no se halla a sí mismo en su vida con la familia apropiadora (una vida signada por el maltrato y la violencia de su apropiador, Luis Falco), empieza a dudar y busca sus orígenes por su cuenta. El tópico de la "búsqueda del hijo" ha ocupado un lugar central dentro de la producción artística sobre y de los/as hijos/as de desaparecidos/as (Basile, 2019). Sin embargo, el viaje que emprenden los hijos-nietos parte de una situación diferencial: la infancia de estos/as niños/ as transcurrió mayormente en el seno de las familias apropiadoras. Sólo la "restitución", es decir, el conocimiento de la verdadera identidad biológica, les permitió reconocer la filiación quebrada y abrir, de esa manera, un camino de búsqueda hacia ese pasado familiar negado y probablemente nunca imaginado durante esa "otra vida" vivida bajo la "identidad apropiada".

Pero, ¿cómo surge el impulso para emprender esta búsqueda? ¿Qué es lo que enciende la llama de la duda? Las sospechas nacen de lo inexplicable, de lo que no cierra (Mariano descubre que en su casa no hay ninguna foto de su supuesta madre embarazada ni de él recién nacido), pero más aún por el "llamado de la sangre". La sangre, como sinónimo de la filiación, de la pertenencia a un grupo familiar, aparece en el discurso de Abuelas como un sustrato identitario inalterable, que podía ser ocultado por los apropiadores y escondido detrás de una identidad falseada, pero que a la larga terminaba emergiendo para imponerse. La sangre, herencia inmaterial, transmite una serie de caracteres, que son físicos pero también emocionales, psicológicos, culturales y así une de manera invisible e irrevocable a los/as jóvenes apropiados/as con las familias que los/as buscan. La sangre no sólo transmite y une sino que "tira", "llama" y este llamado funciona como una fuerza invisible pero irrefrenable que terminaría conduciendo a cada nieto/a a sobreponerse a la mentira impuesta y reencontrarse con la verdad. Estos elementos aparecen dramatizados en la historia de Mariano/Juan. En una escena vemos el sueño de Mariano (antes de conocer su verdadera identidad): allí se le aparece la figura de una mujer embarazada, encerrada en un cuarto oscuro, con una única luz cenital. No se le ve la cara, pero se la escucha susurrar: "no pasa nada, Juan, tranquilo. Estás con mami". La serie también nos 
muestra cómo los intereses e inclinaciones de Mariano (tales como su solidaridad con sus compañeros de escuela y su militancia territorial ya de joven) desentonan por completo con su familia apropiadora, pero adquieren sentido al conocer la biografía de sus verdaderos padre y madre.

Para el momento de la emisión de Televisión por la Identidad, Cabandié ya se había convertido en una figura pública y en un emblema de los "nietos restituidos" había tomado alcance público con su participación en el acto de recuperación del predio de la ESMA para su conversión en espacio de memoria, el 24 de marzo de 2004, apenas dos meses después de su restitución. Era la primera vez que se visibilizaba a un "nieto", que un "joven recuperado" contaba su historia en un escenario estatalmente legitimado y en el mismo lugar donde había nacido y había sido secuestrado. Las palabras de Cabandié, seguidas del discurso del presidente Néstor Kirchner, no sólo representaron una validación oficial de la causa de Abuelas de Plaza de Mayo, sino que consagraron públicamente al "hijo de desaparecidos" y, muy especialmente, al "nieto recuperado" como una figura de alto reconocimiento y valoración social que se transformó en central en la construcción de sentidos y en las luchas concretas por la restitución de los y las jóvenes que todavía faltan localizar. El capítulo de Televisión por la Identidad concluye justamente con un fragmento de este discurso que refuerza sus principales tópicos:

Bastaron los 15 días que mi mamá me amamantó y me nombró para que yo le diga a mis amigos, antes de saber quién era mi familia, antes de saber mi historia, que yo me quería llamar Juan como me llamó mi mamá durante el cautiverio en la ESMA. En este lugar [el corazón] estaba guardado, en la sangre, Juan. ¡Que nunca más suceda esto! Por favor, que nunca más, que nunca más suceda esto. Gracias, gracias a las abuelas, gracias a todos.

\section{Nietos de la esperanza}

El último capítulo de la serie, "Nietos de la esperanza", presenta una importante diferencia con respecto a los anteriores. En lugar de ser la representación de un caso concreto real (como en "Tatiana” y "Juan"), narra una restitución enteramente ficcional, aunque (según se afirma en una placa al comienzo) basada en diferentes historias reales. Cabe preguntarse las razones de esta decisión, que hasta cierto punto pone en tensión el pacto de lectura de las ficciones testimoniales: la idea de que se basan en la "verdad" que porta el protagonista de los hechos, su vivencia narrada en primera persona. Claro está que siempre se trata de la experiencia subjetiva del testimoniante, que puede ser puesta en diálogo y en confrontación con otros testimonios y versiones divergentes de los mismos hechos. Pero en el procedimiento de ficcionalización, la voz en primera persona tiene el efecto de funcionar como verdad "irrefutable", aquello que el/la lector/a o espectador/a puede confiar en que es "verdad". En "Nietos de la esperanza", todo este procedimiento se encuentra ficcionalizado, lo que podría poner en tensión su verosimilitud. Si esto no ocu- 
rre es porque la fidelidad se obtiene no de un testimonio (que no existe realmente) sino de un referencia externa, Abuelas de Plaza de Mayo, cuya palabra socialmente legitimada nos permite aceptar que esta historia es "creíble", que está construida con retazos de muchas otras que, por algún motivo, se prefirió no representar de forma directa.

El capítulo cuenta la historia de Lucía, narrada por ella en el presente, como si se tratara de un relato testimonial. Ella había sido secuestrada siendo bebé junto con su madre Julia, quien además estaba embarazada. Después de dar a luz en cautiverio, Julia fue separada de sus dos hijos, con la excusa de que serían entregados a su familia, lo que nunca ocurrió. En paralelo, el relato nos presenta a los Medrano, un matrimonio de clase alta. La mujer acaba de perder por segunda vez un embarazo. En medio de la crisis que esto genera en la pareja, el hermano de su esposo, que trabaja en el Hospital Militar, le comenta que puede conseguirle un bebé. Algunas escenas después vemos a Medrano llegar con una bebé de varios meses de vida a la casa, que no es otra que Lucía.

En un salto temporal, el relato nos presenta a los padres de Julia que han podido recuperar los restos de su hija y están buscando a su nieta. La empleada doméstica ve la foto de la niña en la televisión y reconoce allí a Florencia, la supuesta hija de los Medrano. A pesar de sus dudas, realiza la denuncia anónima en Abuelas, lo que le permite a Esther, la abuela de Lucía, acercarse hasta el hogar y la niña para confirmar su identidad.

Las escenas finales muestran el proceso judicial de la restitución, en el que el juez de la causa, psicólogas y otros profesionales intervinientes intentan concretarla, a pesar de la oposición de los Medrano y cierta reticencia inicial de la niña, que reproduce comentarios y prejuicios de sus apropiadores. Al igual que en las dos entregas anteriores, el capítulo concluye con testimonios reales de nietos/as restituidos/as y de hijas de desaparecidos/as que (como el personaje ficcional de Lucía) buscan a sus hermanos/as también apropiados/ as, con mensajes dirigidos a los jóvenes que pudieran dudar de su verdadera identidad.

"Nietos de la esperanza" retoma tópicos que ya se habían desarrollado en las dos historias previas: la irrupción del terrorismo de Estado en la normalidad familiar con los secuestros y las desapariciones; los partos en cautiverio (aunque aquí se detiene un poco más en la representación de la vida de las detenidas embarazadas en los centros clandestinos, este tema ya había aparecido en "Juan"); la artesanal e ingeniosa lucha de Abuelas, con sus tareas detectivescas; el encuentro con la verdad como una liberación y el punto de partida para la elaboración de una nueva subjetividad. Los dos elementos novedosos del capítulo son la participación judicial en las restituciones de niños y niñas apropiadas en los primeros años de democracia y la presentación de los/as hijos/as de desaparecidos/as que buscan a sus hermanos/as apropiados/as.

Desde la transición a la democracia, la Justicia fue un escenario decisivo en las disputas por las restituciones. Esta instancia era utilizada por los apropiadores y sus defensas para impedir, o al menos demorar, la confirmación de la identidad de los/as niños/as y su regreso con sus familias biológicas. El capítulo muestra a un magistrado que apoya la restitución con argumentos que retomaban el punto de vista de Abuelas: no importa de cuántos bienes materiales hayan rodeado al niño o la niña, si su crianza se basó en la violencia de origen y en la mentira su situación es equivalente a la esclavitud. Se trata de nociones que han aparecido en sentencias y fallos reales. Sin embargo, hubo a la par numerosos jueces 
(incluso de la Corte Suprema) que dictaminaron en contra de las restituciones, muchas veces bajo una intensa presión de diferentes medios de comunicación (Regueiro, 2013; Laino Sanchis, 2020).

Así como los "nietos restituidos" se constituyeron en estos años como las figuras destacadas en la difusión y las campañas públicas de Abuelas, en el marco del activismo de la organización empezaron a tener cada vez más protagonismo otros hijos e hijas de desaparecidos/as. De manera individual o través de las "comisiones de hermanos" de H.I.J.O.S., muchos/as jóvenes habían comenzado sus propias búsquedas de sus hermanos/as apropiados/as (Diz, 2019, Laino Sanchis, 2020a). Su aparición en Televisión por la Identidad marcó un hito: era la primera vez que eran integrados a una acción promovida por Abuelas. Esta presencia es sintomática de un nuevo momento en la historia de las búsquedas de los "niños apropiados", una suerte de traspaso generacional de la lucha.

\section{Reflexiones finales}

Como hemos podido ver a lo largo de este trabajo, Televisión por la Identidad contribuyó a difundir entre un público masivo el problema de la apropiación de niños/as y la lucha pasada y presente de Abuelas por encontrarlos/as y restituirlos/as. En las tres historias (dos testimonios ficcionalizados y una creación completamente ficcional construida sobre fragmentos de casos reales) que componen la miniserie se hace presente la voz de Abuelas, a través de los de tópicos clásicos de su discurso y de la representación de las diferentes etapas de su lucha. De esta forma, la serie tematiza la represión, los secuestros, las desapariciones y apropiaciones ejecutadas por el Terrorismo de Estado como traumático momento de quiebre en las vidas de las familias afectadas; la creatividad y coraje de las "tareas detectivescas" como táctica desarrollada en plena dictadura para emprender la búsqueda de sus nietos/as; la disputa al discurso castrense que afirmaba que los niños y niñas que estaban buscando habían sido "abandonados/as" por sus madres y padres; la diferenciación entre adopción y apropiación; el "llamado de la sangre" como hilo intangible que une y tira al joven apropiado con su pasado y su filiación negada; la importancia de la restitución de la identidad biológica como liberación de una mentira esclavizante y la puerta a una nuevo futuro que inicia con el conocimiento del verdadero nombre y la verdadera familia. Si bien la historia y la voz institucional de Abuelas son muy fuertes, la serie propone también un desplazamiento generacional del sujeto enunciativo, semejante al que se observaba en otras iniciativas de la misma época: el eje narrativo pasan a ser las vivencias y los testimonios de los nietos y las nietas que pudieron recuperar su verdadera identidad biológica. En la misma línea que otros dispositivos de difusión de Abuelas de esos años (como los spots televisivos), la dramatización de estas historias se complementa con los testimonios directos de los nietos y nietas. Al centrarse en ellos/as y darles la palabra (como personajes de ficción y también como testimoniantes reales, al final de cada capítulo), la serie contribuyó a consolidar al "nieto/a restituido/a" como una figura pública de gran relevancia y un actor clave en las estrategias de búsqueda de los/as niños/as apropia- 
dos/as. Sus testimonios también proliferaron por fuera de los canales institucionales de la organización y se materializaron en libros, documentales y entrevistas televisivas ${ }^{4}$.

A lo largo de sus tres capítulos, la miniserie invita a pensar el problema de la identidad en el caso de la apropiación de niños/as en dos dimensiones. Por un lado, como queda claro, es un problema subjetivo, individual, inherente a cada una de las personas que fueron arrebatadas de sus familias y sufrieron la falsificación de sus nombres y el ocultamiento de sus orígenes y su pasado. La historia muestra el camino que transitan quienes, en diferentes momentos de su vida, logran descubrir la verdad. En este sentido, además del público general, la serie apuntaba a un espectador en particular: los y las jóvenes que pudieran estar dudando de su identidad. La serie los anima a dar el paso para conocer sus verdaderos orígenes. No esconde que el camino que están por iniciar será complejo, pero les asegura que solo a partir del conocimiento de la verdad podrán (re)elaborar libremente su propia identidad.

Al mismo tiempo, empero, la miniserie hace énfasis en los orígenes históricos, políticos y sociales de estos conflictos identitarios. El derecho a la identidad de estos jóvenes fue atacado y denegado por el terrorismo de Estado y su plan sistemático de desaparición de personas. La vulneración de este derecho, como legado trágico de aquel periodo, pervive en democracia en cada niño/a, joven o adulto/a que vive sin conocer aún su verdadera historia y su verdadera familia biológica. Por ende, el reclamo por su localización e identificación no debe ser la tarea solitaria de un grupo de familias, como si se tratara de un interés privado. Es la sociedad en su conjunto la que debe acompañar esta lucha (se lee como subtexto en la miniserie) para que este crimen permanente cese y se pueda reconstituir el tejido social roto por el poder dictatorial.

Esta segunda dimensión del problema de la identidad nos remite al carácter político de la miniserie. Los estudios sobre cine han considerado a las producciones fílmicas como tecnologías de representación, prácticas sociales y culturales en la que se construyen imágenes o visiones del mundo atravesadas por las condiciones sociohistóricas del momento de su realización y exhibición (Colaizzi, 2007; Comolli, 2002). "Esto implica producción de significados que dialogarán con el sujeto espectatorial en términos de una dialéctica discursiva" (Tornay y Alvarez, 2020: 165). Retomando lo señalado por Lizel Tornay y Victoria Alvarez, consideramos que la lógica figurativa de las producciones audiovisuales, "más allá de exhibir el mundo, construye sentidos que dialogan y disputan con otros vigentes" por lo que "no solo se presentan como fuentes para el historiador sino también operan como agentes en la construcción de la historia y en su agencia pueden producir intervenciones políticas significativas" (Tornay y Alvarez, 2020: 161).

A partir de lo que hemos analizado, podemos decir que Televisión por la identidad constituyó una intervención política que buscó difundir y popularizar el reclamo de Abuelas, exponer sus argumentos y posiciones y llegar a los destinatarios primordiales de su mensaje: sus nietos y nietas apropiados/as. Si bien, como señalamos, la serie salió al aire en un momento de nuevo auge del movimiento de derechos humanos, en el que contaron con apoyo estatal, no debemos perder de vista que seguía habiendo grupos minoritarios que se manifestaban en defensa de los represores, contra la reapertura de los juicios por delitos de lesa humanidad y que se expresaban en los medios de comunicación. Por lo que, para 
la causa de Abuelas, el hecho de que hubiera una miniserie en uno de los canales más vistos de la televisión de aire, en un horario central, con altos niveles de rating significó una intervención política significativa.

\section{Bibliografía}

Arreche, A. (2012). El teatro y lo político. Teatro x la identidad (2001-2011): Emergencia y productividad de un debate identitario. Revista Gestos, 27 (53), 105-124

Basile, T. (2019). Infancias. La narrativa argentina de HIJOS. Villa María: Eduvim.

Catoggio, M. S. (2014). La trama religiosa de las redes humanitarias y del activismo transnacional en las dictaduras del Cono Sur de América Latina. En S. Jensen y S. Lastra (Eds.) Exilios: Militancia y represión. Nuevas fuentes y nuevos abordajes de los destierros de la Argentina de los años setenta (pp. 187-213). La Plata: Edulp.

Colaizzi, G. (2007). La pasión del significante. Teoría de género y cultura visual. Madrid: Biblioteca Nueva.

Comolli, J.L. (2002) "El espejo de dos caras". En G. Yoel, Imagen, política y memoria. Buenos Aires: Libros del Rojas (UBA), 159-192.

Da Silva Catela, L. (2005). Un juego de espejos: violencia, nombres, identidades. Un análisis antropológico sobre las apropiaciones de niños durante la última dictadura militar argentina. Revista Telar (2-3), 125-140.

De Vecchi Gerli, M. (2010). “¿Y vos, sabés quién sos?” La identidad asociada a la apropiación ilegal de niños en la última dictadura militar argentina como tema público en Buenos Aires. [Tesis de Maestría. Instituto Mora, México].

Diz, M. L. (2016). Teatro x la Identidad: Un escenario para las luchas por la configuración de sentidos sobre la apropiación de menores y la restitución de la identidad. [Tesis de doctorado en Ciencias Sociales. Facultad de Ciencias Sociales, Universidad de Buenos Aires]. -------. (2019). Abuelas de Plaza de Mayo, hijos de desaparecidos, nietos recuperados y hermanos: de las 'labores detectivescas' a las acciones y producciones culturales, artísticas y mediáticas. Hallazgos [online], 16 (31), 61-89.

Filc, J. (1997). Entre el parentesco y la política. Familia y dictadura, 1976 - 1983 Buenos Aires: Biblos.

Gatti, G. (2011). Identidades desaparecidas. Peleas por el sentido en los mundos de la desaparición forzada. Buenos Aires: Prometeo.

Laino Sanchis, F. (2018). Sentidos en disputa: la problemática de los 'niños desaparecidos' durante la transición democrática argentina (1982-1984). Question, 1 (58)

------. (2020a) De "niños desaparecidos" a "nietos restituidos": actores, escenarios y discursos en torno a los procesos de búsqueda y restitución de los/as niños/as apropiados/as durante la última dictadura en Argentina (1976-2004). [Tesis de doctorado en Historia. IDAES- Universidad Nacional de San Martín].

------. (2020b). Salir al mundo en tiempos de dictadura: Abuelas de Plaza de Mayo y las redes transnacionales de derechos humanos (1977-1983). Revista Quinto Sol, 1 (24), 1-22 
Landau, E. (2006). Montecristo, la historia negra argentina hecha telenovela. Chasqui”. Revista Latinoamericana de Comunicación, (96), 56-61.

Lvovich, D. y Bisquert, J. (2008), La cambiante memoria de la dictadura. Discursos públicos, movimientos sociales y legitimidad democrática. Buenos Aires: Biblioteca Nacional/ Universidad Nacional de General Sarmiento.

Quintana, M. M. (2016). Emergencia y agencia de Abuelas de Plaza de Mayo: un análisis del proceso de subjetivación político-discursiva de la organización y de su producción de fundamentos de identidad en torno de los niños y jóvenes apropiados/restituidos. [Tesis de Doctorado, Universidad de Buenos Aires, Facultad de Filosofía y Letras].

Regueiro, S. (2013). Apropiación de niños, familias y justicia. Argentina (1976-2012). Rosario: Prohistoria.

----.. (2014). De secuestros y localizaciones de niños y niñas "desaparecidos/as": los albores del activismo de Abuelas de Plaza de Mayo. Zona Franca. Revista del Centro Interdisciplinario sobre Mujeres, 12 (23), 37-45.

Ricoeur, P. (1996). Sí mismo como otro. Madrid: Siglo XXI.

Soler Azorín, L. (2015). Teoría y evolución de la novela latinoamericana. [Tesis de doctorado, Universidad de Alicante].

Tornay, L. y Alvarez, V. (2020). La violencia sexual es política. Un análisis de "Campo de batalla, cuerpo de mujer" (Fernando Alvarez, Argentina, 2013). Cuadernos del Centro de Estudios de Diseño y Comunicación (95), 161-172

\section{Fuentes}

Castillo, M. (23 de mayo de 2018). Entrevista a Marcelo Castillo realizada por Fabricio Laino Sanchis en Buenos Aires.

Respighi, E. (21 de octubre de 2007). En esto, el músculo que más trabaja es el corazón. Página 12. Recuperado de https://www.pagina12.com.ar/diario/suplementos/espectaculos/8-8031-2007-10-21.html

Sfiligoy Ruarte Britos, T. (19 de julio de 2017). Entrevista a Tatiana Sfiligoy Ruarte Britos realizada por Fabricio Laino Sanchis en Buenos Aires.

Stiletano, M. (24 de octubre de 2007). Más que una identidad en juego. La Nación. Recuperado en https:/www.lanacion.com.ar/espectaculos/television/mas-de-una-identidaden-juego-nid955874/

Trzenco, N. (22 de octubre de 2007). Estreno: hoy comienza Televisión por la identidad, por Telefé. Reconstruyendo la historia en la pantalla, La Nación. Recuperado de https://www. lanacion.com.ar/espectaculos/television/reconstruyendo-la-historia-en-la-pantallanid955288/

Veiga, C. (29 de junio de 2018). Entrevista a Clarisa Veiga realizada por Fabricio Laino Sanchis en Buenos Aires. 


\section{Notas:}

1. Entre las películas estrenadas que abordan esta temática se encuentran los documentales Botín de guerra (David Blaustein, 1999); Nietos (identidad y memoria) (Benjamín Ávila, 2004), ¿Quién soy yo? (Estela Bravo, 2007), Victoria (Adrián Jaime, 2008), Chicha, esperanza y dolor (Guillermo Kancepolsky y Rosa Teichmann, 2008), Estela (Silvia Di Florio y Walter Goobar, 2008), Hermanos de sangre. La búsqueda continúa (Fabián Vittola, 2008) y La parte por el todo (Andrés Martínez Cantó, Santiago Nacif Cabrera y Roberto Persano, 2015). También se produjeron varios películas de ficción sobre la temática, entre ellas Los pasos perdidos (Manane Rodríguez, 2001), Cautiva (Gastón Biraben, 2003), Figli/Hijos (Marco Bechis, 2005), Aparecidos (Paco Cabezas, 2007), Adopción (David Lipszyc, 2009), El recuento de los daños (Inés de Oliveira Cézar, 2010), Eva \& Lola (Sabrina Farji, 2010) y Verdades verdaderas (Nicolás Gil Lavedra, 2011).

2. Según señala Marcelo Castillo en la entrevista que le realizamos, la consigna fue utilizada por primera vez en 1998 como parte del isotipo que desarrolló para Abuelas Raúl Bellucia, un diseñador gráfico que realizó diferentes colaboraciones con la organización en esos años. El isotipo consistía en una flecha con la consigna arriba y los datos de la organización adentro y abajo. (M. Castillo, comunicación personal, 23 de mayo de 2018). Posteriormente, la consigna se popularizaría con el spot publicitario "Del otro lado del espejo", del año 2000 (De Vecchi Gerli, 2010; Diz, 2016).

3. La primera restitución fue la de los hermanos Anatole y Victoria Julien Grisonas, hijos de Mario Roger Julien y Victoria Lucía Grisonas, militantes uruguayos del Partido por la Victoria del Pueblo (PVP). Toda la familia fue secuestrada en Buenos Aires en septiembre de 1976, en el marco de la coordinación represiva entre las dictaduras del Cono Sur conocida como "Plan Cóndor". Mario y Victoria estuvieron en cautiverio en el centro clandestino de detención "Automotores Orletti". Años después, sus hijos fueron localizados en Chile viviendo con una familia adoptiva. Las fuentes locales señalaban que los niños habían sido hallados "abandonados" en una plaza de Valparaíso en 1977. Su localización, en la que intervinieron el Alto Comisionado de las Naciones Unidas para los Refugiados (ACNUR), la Vicaría de la Solidaridad de Chile y Clamor de Brasil, resulta un claro ejemplo de la operatividad de las redes de solidaridad de organismos regionales y transnacionales de derechos humanos. Sobre este caso, véanse los trabajos de Regueiro (2014) Cattoggio (2014) y Laino Sanchis (2020b).

4. Juan Cabandié, que ya tenía una trayectoria previa de militancia social, consolidó en los años siguientes una importante carrera política como dirigente de la agrupación juvenil kirchnerista La Cámpora. Fue legislador de la Ciudad Autónoma de Buenos Aires (2007-2013), diputado nacional por el mismo distrito (2013-2019) y al momento de la escritura de este artículo se desempeñaba como Ministro de Ambiente y Desarrollo Sostenible de la Nación.

5. Sólo por mencionar algunas de las producciones más relevantes centradas en las historias de vida de estos/as nietos/as podemos señalar, entre los documentales, Nietos (identidad y memoria) (Benjamín Ávila, 2004), ¿Quién soy yo? (Estela Bravo, 2007) y Victoria (Adrián Jaime, 2008). En cuanto a los libros, encontramos De vuelta a casa. Historias de 
hijos y nietos restituidos de Analía Argento (2008) y En el nombre de sus sueños. 12 historias de vida de hijos de desaparecidos de Tatiana Sfiligoy y Danilo Albín (2013) y El nieto: La trágica y luminosa historia de Ignacio" Guido" Montoya Carlotto de María Seoane y Roberto Caballero (2015).

\begin{abstract}
During the last military dictatorship in Argentina, around 500 children were appropriated within the framework of the systematic plan for the disappearance of persons. Since then, family members and human rights organizations, especially Abuelas de Plaza de Mayo (Grandmothers of Plaza de Mayo), undertook the struggle to locate them and restore them to their legitimate families. In this process, they elaborated different concepts and representations around the question of subjective identity and its relationship with genetics, kinship, memory, and history. At the beginning of the 2000s, the cause of Abuelas gained momentum, mainly because many of those appropriated children, by then young men and women, undertook on their initiative the search for their true origins. This led to an increase in the number of identity restitutions achieved. In this historical context, Abuelas promoted different cultural and media initiatives to consolidate the social legitimacy of its cause. They also expected to reach the main addressee of their message: young people who doubted their true biological identity. One of these initiatives was Televisión por la Identidad, a three-chapter miniseries broadcast by the Telefé channel in 2007. The series reached a large audience and had a notable impact on the dissemination of Abuelas's message. In this article, we propose to analyze this audiovisual production to investigate the meanings around the notion of "identity" it presents. With this aim, we will analyze its production context and the narrative structure of its three chapters, which will allow us to investigate the discourses and representations about the crime of appropriation and the search and restitution processes that appear there. We will show how these processes, with the particularities of each case portrayed, appear linked to the construction of an identity of the restored grandchildren, both in a biological as well as a family, social and subjective dimension.
\end{abstract}

Keywords: Television for Identity - Abuelas de Plaza de Mayo - Representations - Appropriation of children - Restitution - State terrorism in Argentina

Resumo: Durante a última ditadura militar argentina, cerca de 500 meninos e meninas foram apropriados no âmbito do plano sistemático de desaparecimento de pessoas. Desde então, familiares e organizações de direitos humanos, especialmente as Abuelas de Plaza de Mayo (Avós da Plaza de Mayo), empreenderam a luta para localizá-los e devolvê-los às suas famílias legítimas. Nesse processo, elaboraram diferentes conceitos e representações em torno da questão da identidade subjetiva e sua relação com a genética, o parentesco, a memória e a história. No início dos anos 2000, a causa de Abuelas ganhou impulso, em grande parte porque muitas crianças apropriadas, então já jovens, empreenderam por iniciativa própria a procura das suas verdadeiras origens, o que levou a um aumento dos 
reembolsos e a uma maior visibilidade das mesmas. Neste contexto, Abuelas promoveu diversas iniciativas culturais e midiáticas com o objetivo de consolidar a legitimidade social da sua causa e chegar aos seus principais destinatários: jovens que duvidavam da sua verdadeira identidade biológica. Uma dessas iniciativas foi Televisión por la Identidad, uma minissérie em três partes veiculada pelo canal Telefé em 2007. A série alcançou grande audiência e teve um impacto notável na divulgação da mensagem de Abuelas.

Neste artigo, nos propomos a analisar essa produção audiovisual para investigar quais os sentidos que ela constrói em torno da noção de "identidade". Para tanto, analisaremos seu contexto de produção e a estrutura narrativa de seus três capítulos, o que nos permitirá investigar os discursos e representações sobre o crime de apropriação e os processos de busca e restituição que aí aparecem. Mostraremos como esses processos, com as particularidades de cada caso da pessoa retratada, aparecem ligados à construção de a identidade dos netos restaurados, tanto na dimensão biológica quanto na dimensão familiar, social e subjetiva.

Palavras chave: Televisão pela Identidade - Abuelas de Plaza de Mayo - Representações Apropriação de crianças - Restituição - Terrorismo de Estado en Argentina.

[Las traducciones de los abstracts fueron supervisadas por el autor de cada artículo] 